\title{
Low immunisation uptake: Is the process the problem?
}

\author{
Peter M Harrington, Catherine Woodman, William F Shannon
}

\begin{abstract}
Objective-To examine mothers' satisfaction with the process of immunisation and its possible contribution to suboptimal immunisation uptake.

Design-In depth interviews with mothers.

Setting-Two Community Care Areas, Dublin city, Ireland.

Participants-In depth interviews of 23 mothers of children 1-2 years old, recruited purposively from a birth cohort born in 1994.

Main results-Mothers preferred general practice to Health Centre immunisation (11:5) for predominantly emotional compared with practical reasons $(4: 1)$. Health Centre immunisation was seen, at times, as unacceptably rough and inhuman. Many mothers experienced severe emotional distress at the prospect of inflicting the pain of immunisation on their babies. The non-empathic stance of some immunising doctors was unacceptable to mothers. They valued attempts by health professionals to acknowledge the pain of immunisation and to engage with their baby. Adverse experiences contributed to deferral of future visits and to defaulting behaviour.

Conclusions-Low empathy mass immunisation in clinic type settings may be unacceptable to mothers in the $1990 \mathrm{~s}$, and may in part explain suboptimal uptake in health care systems that use such clinics. (F Epidemiol Community Health 2000;54:394-400)
\end{abstract}

Immunisation uptake in the Republic of Ireland remains below the World Health Organisation target. ${ }^{1}$ This is also the case in many other developed countries, particularly among disadvantaged groups..$^{2-8}$

Studies examining the maternal aspects of this phenomenon have established the following factors as contributing to suboptimal uptake: rising parity, ${ }^{7-13}$ low knowledge regarding immunisation, particularly the timing of the next due vaccine, ${ }^{14-18}$ inadequate antenatal care (probably representing poor engagement with medical services), ${ }^{19-21}$ family dysfunction ${ }^{22}$ and inadequate social support. ${ }^{20}{ }^{23-26}$ Studies using Social Cognition Models ${ }^{16}$ 27-31 have provided useful insight, particularly the fear of vaccine harm as a barrier to immunisation. Yet the influence of variables incorporated in such models account for a relatively small proportion of the variance, when compared with simultaneously measured demographic variables. $^{2431}$
Much less attention has been paid to the influence of factors at the health services interface in facilitating or hampering immunisation behaviour. Mothers point to long waiting times and inconvenient hours. ${ }^{32}{ }^{33}$ Qualitative studies point additionally to difficulty obtaining an appointment, crowded clinics and the problem of bringing and minding other children. ${ }^{34-36}$ There is, however, little published data, either quantitative or qualitative, on maternal attitudes to the actual process of immunisation.

As part of a wider study exploring immunisation decision making and experiences of the immunisation services in a community with suboptimal immunisation uptake, this study sought to establish the response of mothers to the immunisation process. Specifically, their emotional response to witnessing the procedure, their satisfaction with the process and its possible contribution to defaulting behaviour.

Dublin mothers, at the time of the study, obtained Measles/Mumps/Rubella (MMR) vaccine exclusively and without charge from their general practitioner (GP). Preceding primary vaccines were available without charge twice monthly at all Health Board Health Centres, or from GPs where most mothers incurred fees. Immunisations at Health Centres were administered by doctors, more usually male, with a variety of training experiences and remunerated per session.

\section{Methods}

As part of a wider prospective study examining suboptimal childhood immunisation uptake in Dublin city, a cohort of 343 mothers delivering their babies in a maternity hospital from March to August 1994 was recruited during their confinement. Recruited mothers were unaware that the specific focus of the study was childhood immunisation, nor were they informed of the qualifications of the interviewing researcher (either $\mathrm{CW}$ or $\mathrm{PH}$ ). Written consent was obtained to partake in the "The Child Care Study", the purpose of which was to examine the delivery of health services to infants. Consent included permission to access the infant's health board and GP records, and telephone or postal follow up to examine satisfaction. Using a structured interview, a range of data was gathered including sociodemographic variables, satisfaction with primary care services, health beliefs regarding infectious diseases and the mother's intention to obtain primary immunisations for her child. The immunisation behaviour of all mothers on behalf of their babies was established at the time of the infant's first birthday from health board and GP records. The statistical relation between the 
quantitative data gathered and the subsequent immunisation behaviour of the mothers in the cohort forms the basis of a separate paper.

During the structured interview, mothers meeting one or more of the following four criteria were identified as suitable for follow up in depth interview. Mothers who: (1) were uncertain as to their likely immunisation behaviour; (2) spontaneously expressed anxieties regarding immunisation either because of personal or hearsay accounts of vaccine harm; (3) favoured immunisation because of their experiences of measles or whooping cough; and (4) favoured immunisation as a means of protecting their baby. In keeping with a qualitative methodology, the aim was to purposively select mothers from a range of backgrounds and with a range of experiences and opinions regarding immunisation. A total of 62 mothers were so identified with seven meeting more than one criterion. A fifth group comprised defaulting mothers, whose baby's immunisation record at 12 months showed incomplete uptake. Travellers, schoolgirls, mothers delivering prematurely or with a previous history of depression, drug abuse or alcoholism were excluded from qualitative follow up. The reasons for excluding them relate to their atypia regarding the cohort under study, the possibility that their mood might make interviewing difficult or invalid and anticipated difficulties in re-establishing contact during the child's second year.

Mothers were contacted by telephone or letter and asked to consent to in depth interview, starting with those meeting more than one qualifying criterion and attempting to preserve a balance of inclusion criteria. No new data were obtained after interviewing 23 mothers by which time 40 mothers in all has been contacted. Of the 17 who declined, four did not wish to be tape recorded, three felt that the usual demands of child care would not permit the time, six had moved leaving no forwarding address and the remaining four had left Ireland. In depth interview of the 23 consenting mothers was carried out during their child's second year. Twenty one interviews were conducted in the mother's home and two, for the convenience of mothers, in the Department of General Practice. This group ranged in age from 20-43 years and included nine first time mothers. The Social Classification of the mothers interviewed, in accordance with Irish methods of classification, is as follows: SE1-3, SE2-3, SE3-3, SE4-8, SE5-2, SE6-4. Table 1 outlines the immunisation uptake for these 23 mothers.

The unstructured maternal interviews explored the impact of lay and professional influences on their decision making regarding immunisation and their experiences of the immunisation process. Interviews lasted 45-90 minutes and were tape recorded. Verbatim transcripts were analysed with the assistance of NUD.IST software, ${ }^{37}$ a computer package designed to assist with the management of non-numerical data in qualitative research. This programme facilitates the appropriate categorisation and recategorisation of text units from within the transcribed interviews, in the
Table 1 Immunisation behaviour and status of the 23 babies of the mothers interviewed at 12 months of age

\begin{tabular}{llr}
\hline Vaccination choice & Vaccination status & \\
\hline Diphtheria/tetanus & Complete & 1 \\
& Incomplete & 2 \\
Diphtheria/tetanus/pertussis & Total & 3 \\
& Complete & 16 \\
& Incomplete & 4 \\
Hib & Total & 20 \\
& Complete & 16 \\
& Incomplete & 6 \\
& None & 1 \\
& Total & 23 \\
\hline
\end{tabular}

search for recurrent themes and their meanings. In the absence of a body of literature concerning the process of immunisation, the theoretical framework used was that of grounded theory, ${ }^{38}{ }^{39}$ in which the researchers constantly revised the analysis by returning to transcripts, theoretically sampling for new participants, re-examining their own values and by comparing concepts and theories in the literature with that of respondents. ${ }^{38-40}$ In this way theory was inductively derived from the data representing the experiences and perceptions of the mothers interviewed.

Study findings in relation to the introduction of Haemophilus influenzae type b (Hib) vaccine are published elsewhere. ${ }^{41}$ Mixed qualitative and quantitative data on maternal decision making in the area of immunisation are presently being prepared. This paper focuses solely on mothers' responses to the physical process of immunisation. Verbatim quotations included were selected from the range of mothers to emphasise study findings.

\section{Results}

PREFERRED IMMUNISATION LOCATION

As all mothers must attend their GP for MMR vaccine and 20 of the 23 mothers attended health centres for the other primary vaccines, the great majority of our respondents have sufficient experience of both locations to make a valid judgement. Sixteen expressed a definite preference for an immunisation site. These favoured general practice over health centres in the ratio 11:5. Issues in this decision, outlining the characteristics of both locations as perceived by the mothers, are shown in table 2 and expanded upon in the text.

Preferred immunisation location - health centres Immunising mothers had both practical and emotional needs. Health centres met these needs least well, particularly the emotional needs. Mothers resented the lack of time for discussion and explanation regarding the antigens and the decision to immunise. Clearly, the decision as to which vaccines to consent to had to be made in advance of the health centre visit. Attempts by mothers to discuss this issue during an immunisation clinic were perceived as distracting busy immunising doctors from the task at hand. These doctors, in turn, seemed to dislike being challenged with questions concerning individual vaccines, or about the immunisation procedure, and at times seemed somewhat authoritarian in their approach. One mother alleged that the Hib vaccine, which had 
Table 2. Expressed preferences of the 23 mothers for an immunisation location

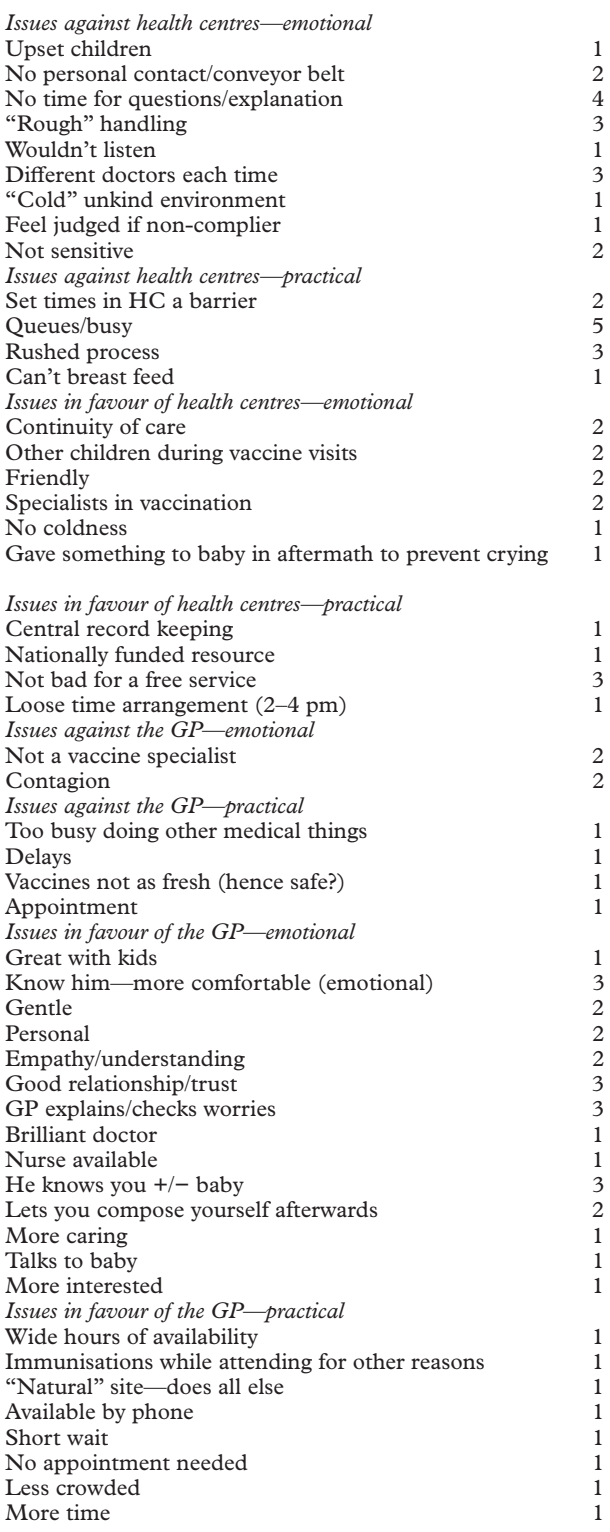

been added to the immunisation schedule since her attendance with an older sibling, was given without an informed explanation. Another felt that her specific queries regarding immunisation were not satisfactorily dealt with before the vaccines were given. Mothers spoke of a lack of personal contact and felt poorly engaged in the process.

"And if you kind of ask them any questions they are really eager to get rid of you because they're eager to get in and get out, the vaccination doctors, you know." (Mother 23).

Mothers painted a rather chaotic picture of many of their visits. Waiting times varied considerably. They were prepared to wait 90 minutes or more, but were frequently seen in under 45 . Health centres were seen as efficient places, any delays a consequence of their stretched workload. However, mothers disliked the queues and delays that they believed led to rushed immunisation. On the other hand, the speed of the procedure was seen as minimising any discomfort for the baby and their experience was qualified as being good value for no money.

"Well today is the day and you just put everything else aside, forget dinners, forget housework and just go and just...I mean, I don't go with the impression that I have to be back at a certain time when I am doing something like that. You just say expect me when you see me. But I know a lot of people do kind of, oh well now, if I am here more than an hour I am going, I'm not waiting." (Mother 20).

"They don't even get time to really talk to you. You walk in the door with your baby in your arms. You sit down. They say give us her left arm. You give her the left arm, inject her. Now hold her tight and then you have to go straight away. There's no personal contact whatsoever...If you kind of ask questions you are being rushed out, you know what I mean, for the next person to come in. Because it's in out, in out. But in saying that, they do provide a good service because you are getting injections free." (Mother 23).

Mothers frequently used non-human, particularly animal, imagery to describe their experiences-“conveyor belt", "just a number", "cat", "dog", "stuffed chicken". Four mothers spontaneously used the analogy of cattle. These images seemed to arise from a perceived lack of compassion on the part of some immunising doctors and nurses. Screaming children emerging after receiving vaccines added to the trauma of the occasion. Three mothers complained of "rough" handling of their babies. Three complained about meeting a different doctor on one or more visits, adding to the sense of an impersonal service.

'It's a cattle market or something. It's a like baby belt conveyor sort of conveyor belt. Baby and mother and baby and like harassed mother trying to remain calm and rational. And screaming children and like all the other children. Like going in and getting this is like, in you go, like, bang. Next, you know...It doesn't do a hell of a lot for the mother's psychology either, you know, especially the first time mothers." (Mother 14).

"Well the whole place, like I mean it was a bit cold. It was like cattle, you know. In for the injection, shuffled out. As I said the doctor made me feel stupid 'cos I didn't like the needles." (Mother 6).

"More like cattle going in and out. There's so many babies, you know what I mean, going in and out. But when you do go in to the actual doctor, like, they are very nice. Like they do listen to you." (Mother 17).

'It's very hard now, kind of. They just took her arm and took her leg and dump the needle in, you know, that way like. I didn't know the doctor and he didn't know me. And then, as I say, we went down the next time and there was a different doctor.” (Mother 2).

Restricted clinic opening hours were seen as a disadvantage, especially afternoon clinics when other children needed collection from school. Occupying small siblings without play facilities added to the hassle of the day and contributed to defaulting behaviour. Defaulting mothers, with the exception of those who had adverse immunising experiences, still intended to complete their schedules at some 
unspecified future date. They talked in terms of forgetfulness, rather than a true apathy. Almost all were of high parity and pointed to the stresses of child care in a large family. The disadvantages of the clinic as an immunisation location seemed of greater importance to these mothers. The apparent chaos of life in a large family made the prospect of a visit to the clinic even more onerous, especially if it involved bringing other small children. This was particularly so if the family had no transport and if the weather was bad, making defaulting more likely. For these mothers, the tendency for defaulting behaviour to increase with rising parity seemed mostly attributable to an increase in the burden of child care, rather than a true apathy.

"At least with the doctor [referring to the GP] you have the option of going a different day. Where with the...you might remember one day to go to the Eastern Health Board needle clinic and you look out and it could be lashing with rain and you wouldn't want to go around, you know. And you can't go again for maybe two weeks. And you might have forgotten about it again by then." (Mother 5).

"So possibly that was a kind of, I am not going through this again, I am not able for it today, or whatever. Or, he has a dirty nose. Or, he has a bit of a cold so I can't bring him today, Thank God. There's probably a bit of that in it alright." (Mother 13).

Positive experiences referred to the friendly atmosphere, the presence of other children at immunisation sessions and continuity of care through record keeping. Health centre doctors were seen as specialists in immunisation as they carried them out all the time, by comparison with GPs who were perceived as performing them less often.

Preferred immunisation location - general practice General practice was the preferred immunisation site. The content of comments in favour of GPs as immunisers (see table 2) were emotional:practical, in a ratio of $>4: 1$. Mothers felt that they knew their GPs, with the pre-existing relationship helpful during immunisation visits. GPs were seen as more likely to explore worries and to offer explanations. In contrast with statements of rough handling in the health centres, GPs were seen as gentle, caring, more likely to engage the child and more likely to be empathic with the emotional trauma mothers experience when party to the infliction of pain on their children. In this regard, two mothers specifically mentioned that their GP would let them compose themselves after their tears in the immediate vaccine aftermath.

"...just to be able to ring him up and say look it, you know she had the injection this morning and her arm is such. Fust for a bit of feedback, personal feedback. That I wasn't just a woman in a queue."... "I am glad that I had the GP there, especially with the second, because he knew how awful it was on me." (Mother 10).

Practical comments concerned wider hours of availability, including evening appointments and a less crowded environment. This was seen as likely to suit defaulters who could immunise during surgery visits for other reasons. Two
KEY POINTS

- Mothers prefer general practice to health centre immunisation, for predominantly emotional reasons.

- Health centre immunisation is seen, at times, as unacceptably rough and inhuman.

- Many mothers experience severe emotional distress at the prospect of being party to the infliction of the pain of immunisation on their babies.

- Adverse experiences contribute to deferral of future visits and to defaulting behaviour.

- The non-empathic stance of some immunising doctors is unacceptable to mothers. Mothers value attempts by health professionals to acknowledge the pain of immunisation and to engage their baby.

mothers expressed concerns about the risks of contagion, particularly from coughing adults in the GP's waiting room.

Many mothers did not, however, see their GP as a potential location for vaccines other than MMR. Information gathered at antenatal classes, during BCG immunisation and to a lesser extent through the public health nurse (PHN), reinforced the health centre as the site for immunisation. When asked about their options when seeking an immunisation location, six mothers who were aware that their GP gave MMR vaccine were unaware that he could also give the other primary vaccines.

KNOWING THE IMMUNISING DOCTOR

Mothers were roughly equally divided in their sentiments regarding the importance of knowing the immunising doctor. Knowing had two separate components. An emotional component, centred on the doctor's knowledge of the mother as a person-and by implication the mother's knowledge of her doctor-with a more empathic view of the trauma experienced by the mother when immunising. And a cognitive component, centred on the doctor's knowledge of the medical history of the family and baby to prevent any vaccine related harm.

Six mothers felt it important to be emotionally known by the immunising doctor and one the attending nurse, in this case a PHN.

"I would have actually preferred my own doctor to do it, than someone like this man I've never seen. Actually, it was a woman I think the first... two times and on the last occasion it was a man and I even thought he was very rough." (Mother 20).

"I think because you have more trust in him and you just, they are more gentle or something. They are probably not, but you feel that they care more about your baby and they talk to him and they know his name and things like that." (Mother 9).

Five felt it important to be cognitively known by the doctor and one the attending nurse, again a PHN. Of interest, four of these five were either defaulting or had opted against Pertussis vaccine or both. Factual knowledge seemed more important than emotional engagement 
for these mothers in their attempts to avoid vaccine mishap.

"I know he was checked, you know. He did listen to his chest and stuff like that, you know. But I mean it's more than that. It's the history of the parents and maybe even possibly grandparents to whether, you know, vaccinations are going to have any after effects or long term thing, you know." (Mother 18).

For four other mothers gentleness on the part of any immunising doctor was the most important aspect of the encounter, compared with the issue of "being known".

"Well I suppose you are very sensitive about your own children and I don't want people hurting them... and taking it glibly. And I know it has to be done but I wouldn't like somebody just taking out their arm and just putting a needle in it." (Mother 10).

WARMTH-PAIN-ANTICIPATION

Almost all mothers found the idea of inflicting pain on their baby emotionally very upsetting, although acknowledging that the pain was short lived. They talked of steeling themselves, of chain smoking, of praying, of being terrified, traumatised and of being in or close to tears. These mothers were experiencing sometimes severe emotional distress by permitting the infliction of pain on their babies.

"But I think it's heartbreaking. You know it don't last long. It's still heartbreaking, it does hurt. I mean to hear your baby two months old sobbing, you know actually sobbing his heart out 'cos they have been injecting him sort of thing. Yeah it's horrible, it's not nice, not nice at all." (Mother 18).

"It's like your child getting a screech of pain, so it's desperate it is. It's not like he's whingeing or cribbing or crying. It's actually like a screech, you know, that hurt. And they always seem to look at you or something. The little face and the little tears and stuff." (Mother 14).

Comparisons between different doctors and nurses were made largely on the axis, rough to gentle. Mothers valued highly those immunising health professionals who engaged their baby, touched, spoke to or induced a smile from their baby, encouraged them to cuddle their baby in the immediate aftermath and whose demeanour seemed to acknowledge the emotional pain they, the mothers, were experiencing. The lack of continuity through the use of different immunising doctors and nurses at health centres was seen as less than ideal, but would be largely excused if all immunising personnel had such a demeanour. The dispassionate non-empathic stance taken by many immunising professionals was seen as inappropriate and led to reduced satisfaction. Two mothers actively took steps to avoid encountering specific immunising doctors they deemed to have been too rough at previous health centre visits.

"You get some and they are really gentle. There was one particular nurse down there and you get the feeling that she really cared and felt and was more... whereas there was another one, she was very abrupt... and she just kind of grabbed the arm and that was it, you know and I just...God it's cruel...you are really cruel." (Mother 20).

"... and the next time we were to go back, I asked was it the same doctor because I wouldn't have gone in. I thought he was a horrible person. He was just a horrible manner on him and he just jabbed in and out again and there off you go type of thing." (Mother 12).

Many mothers would have subjected themselves to the injection in lieu, if this was possible. A small number admitted to personally hating needles but defaulters were not overrepresented in this group. The fact that the baby was too young to understand and was not amenable to reason added to the trauma. Some mothers disliked being a party to this infliction of pain. Some asked their husbands to bring the baby instead. Others asked a grandmother to accompany them, or looked to a nurse for support. This support was both emotional and practical, including the restraining of the baby during the procedure.

"I won't hold my baby. I won't hold him 'cos like to me they're inflicting pain on him and I don't want to be the one that's holding him down and you know have any part of it really." (Mother 18).

"Support. Moral support, I think. And just support like knowing that there is somebody there for you if you break down or just to help with him really as well." (Mother 9).

The practice of discharging semiclad often crying babies back to the waiting room within seconds of receiving their vaccines, while other mothers queued, added to negative anticipation. These feelings were compounded by recollections of the heel prick (Guthrie) test, carried out at four days of age, with anticipation of a similar level of pain infliction during immunisation. Mothers were universal in their condemnation of this test as placing their babies in a prolonged state of pain and distress.

Mothers whose babies appeared to suffer minimal discomfort at the first vaccine visit, experienced less negative anticipation before the next vaccine. But for many, future visits were still a dreadful prospect. Negative anticipation was also experienced by mothers whose babies suffered short-term local or systemic vaccine reactions. Some of these mothers experienced negative anticipation sufficient to defer their next vaccine visit or to default altogether.

"Half of the babies coming out are coming out in hysterics and he is just sitting there looking at them. What am I going in here for, you know? I felt that he felt I was bringing him in to get something bad done to him." (Mother 22).

"You hear one child screech after they get the injection and like all the children outside in the waiting room stop momentarily and look towards the door and then the noise level starts to go up again.” (Mother 14).

"I am not looking forward to it at all. I could cry now when I think about it. Because even the thought of having to bring her in and get another needle, you know. And then you keep apologising for it, you know, saying I am sorry but you have to have this done."(Mother 21).

\section{Discussion}

Examination of maternal immunisation behaviour, mostly qualitative, has thus far primarily explored the influence of accessibility constraints, time space constraints and gender 
constraints on uptake. . $^{32-364243}$ Working groups ${ }^{44}$ call only for improvements in physical accessibility, the environment and reduced waiting time. There is a paucity of data on the actual process of immunisation as a barrier to optimum uptake.

Our study provides new insights into the often severe emotional distress experienced by many mothers during the immunisation process. Quite clearly, the mothers we interviewed want more time to discuss the vaccines being administered and far less hasty and more empathic immunisation, ideally from a doctor with whom they have some rapport. A separate aspect of our study included in depth interviews and focus groups with GPs and PHNs from the same Community Care Areas as the mothers. Accounts from PHNs confirm the logistics of health centre immunisation, low levels of expressed empathy from some immunising doctors and the refusal of some mothers to return to doctors perceived as too rough. These data provide reassuring triangulation on the validity of our interpretation of the maternal data, as reported here.

Mothers' dislike of restraining their baby during the immunisation procedure has received little regard. Only one study, surveying defaulters in a disadvantaged local authority estate, identifies it as an issue. ${ }^{46}$ Our finding, that many mothers needed emotional support during the process of immunisation, is reinforced by studies praising the availability of a nurse to act in this fashion ${ }^{35}$ and highlighting the use of other accompanying persons for moral support $(12 \%)$, to hold the child $(18 \%)$ or to drive $(14 \%) .{ }^{47}$

General practice was the preferred immunisation site for our mothers, for emotional rather than practical reasons. Australian mothers, like ours, have the option of immunising in a health centre or through their GP. In a study examining the reasons for their choice, ${ }^{48}$ mothers choosing to attend a GP gave " a person known and trusted" as the commonest reason (29\%). Mothers immunising in health centres were motivated more by lower cost $(30 \%)$ and accessibility factors. Relative immunisation performance at both sites was not compared.

But do adverse immunisation experiences contribute to defaulting behaviour, as our findings suggest? The breadth of our qualitative sampling frame to include defaulting mothers and those with anxieties regarding vaccines, as outlined in the Methods section, precludes us from making conclusions in this regard. A literature search of MEDLINE and CINAHL databases, identified only three papers alluding to the problem of dispassionate or rough handling by immunising doctors, ${ }^{35} 4950$ two of which provided some evidence in support of this hypothesis. ${ }^{49}{ }^{50}$ Retrospective structured interviews of parents of 24-30 month old children compared 85 fully immunising, 70 defaulting and 73 refusing Pertussis vaccine. ${ }^{49}$ Half the sample admitted to deferring visits for vaccines with half of these reporting that worries about child distress after immunisation were important or very important contributing factors. Nearly a fifth of those who delayed or defaulted altogether reported previously unsympathetic treatment by clinic staff as a factor in their decision. The authors pointed to the shortcomings of the retrospective methodology and the possible interplay of cognitive dissonance upon study findings.

The second, a qualitative ethnographic exploration of both health professionals and mothers from Haiti, ${ }^{50}$ described mothers' feelings of inadequacy when health professionals were seen to scold them for undernourishing the babies they were bringing for immunisation. This had the potential to contribute to defaulting behaviour. Rudeness and "careless vaccine administration procedures" on the part of some health professionals were an issue for some of the women.

The third used focus groups to explore the attitudes of mothers attending public, private and military immunisation facilities in the USA ${ }^{35}$ a country with low preschool uptake among disadvantaged groups. ${ }^{2}{ }^{45}$ Comments from mothers were remarkably similar to those in our study describing inhuman, rough, and dispassionate treatment particularly from attenders of public facilities. Both public and private mothers disliked the attitude of some health professionals - " They assume you have no sense"..."Like they are doing us a favour." "To the nurse it's just another arm, you know." These mothers also resented the practice of allowing screaming babies to emerge immediately after immunisation thus upsetting other waiting babies. Efforts by health professionals to acknowledge and ameliorate the pain of immunisation were appreciated. Being speedy in the case of multiple injections, engaging the child, distracting the child and using cartoon character plasters were examples of perceived good practice.

Literature on health professionals' views of the process have focused largely on resistance to administering multiple injections. ${ }^{51}$ The Ad Hoc Working Group for the Development of Standards for Pediatric Immunisation Practices in the USA has identified physician reluctance to administer multiple simultaneous vaccinations as a significant contributor to low vaccine uptake. ${ }^{45}$ This resistance has risen with the introduction of universal hepatitis $\mathrm{B}$ vaccination with $37 \%^{52}$ and $59 \%{ }^{53}$ of surveyed physicians unhappy to give three simultaneous vaccines during one visit. A survey comparing physician with parental concerns at the prospect of three or more simultaneous vaccines found physicians to have stronger reservations, mostly with the prospect of inflicting pain. ${ }^{54}$

The mothers in our study seem to be seeking some acknowledgement from health professionals that the process of immunisation is potentially traumatic. Reducing this compassion deficit has the potential to improve immunisation uptake levels. We believe it is time once again to examine not just what we do, but how we do it?

Funding: the authors wish to thank the following for their financial support of this study: The Health Research Board, The Department of Health and The General Practice Unit, Eastern Health Board.

Conflicts of interest: none. 
1 Harrington P, Woodman C, Shannon W. Childhood immunisation uptake in the Republic of Ireland. Ir Med $\mathscr{f}$ 1995;88:153-4.

2 Orenstein WA, Atkinson W, Mason D, et al. Barriers to vaccinating preschool children. $f$ Health Care Poor Underserved 1990; 1:315-30.

3 Zell ER, Dietz V, Stevenson J, et al. Low vaccination levels of US preschool and school-age children (Retrospective assessments of vaccination coverage, 1991-1992). $\mathcal{F} A M A$ 1994;271:833-9.

4 Jarman B, Bosanquet N, Rice P, et al. Uptake of immunisation in district health authorities in England. $B M \mathcal{F}$ 1988;296:1775-8

5 White JM, Gillam SJ, Begg NT, et al. Vaccine coverage: recent trends and future prospects. BMF 1992;304:682-4.

6 Williams IT, Milton JD, Farrell JB, et al. Interaction of socioeconomic status and provider practices as predictors of immunization coverage in Virginia children. Pediatrics 1995;96:439-46.

7 Markland RE, Durand DE. An investigation of sociopsychological factors affecting infant immunization. $A m \mathcal{F}$ Public Health 1976;66:168-70.

8 Marks JS, Halpin TJ, Irvin JJ, et al. Risk factors associated with failure to receive vaccinations. Pediatrics 1979;64:3049.

9 Li J, Taylor B. Factors affecting uptake of measles, mumps, and rubella immunisation. BMF 1993;307:168-71.

$10 \mathrm{Li} \mathrm{J}$, Taylor B. Childhood immunisation and family size. Health Trends 1993;25:16-19.

11 Bobo JK, Gale JL, Thapa PB, et al. Risk factors for delayed immunization in a random sample of 1163 children from Oregon and Washington. Pediatrics 1993;91:308-14.

12 Senior ML, New SJ, Gatrell AC, et al. Geographic influences on the uptake of infant immunisations: 2. Disaggregate analyses. Environment and Planning $A$ 1993;25: 467-79.

13 Schaffer SJ, Szilagyi PG. Immunization status and birth order. Arch Pediatr Adolesc Med 1995;149:792-7.

14 Lieu TA, Black SB, Ray P, et al. Risk factors for delayed immunization among children in a HMO. Am $\mathcal{F}$ Public Health 1994;84:1621-5.

15 Miller LA, Hoffman RE, Baron AE, et al. Risk factors for delayed immunization against measles, mumps, and rubella in Colorado two-year-olds. Pediatrics 1994;94:213-19.

16 Lewis T, Osborn LM, Lewis K, et al. Influence of parental knowledge and opinions on 12-month Diphtheria, Tetanus, and Pertussis vaccination rates. Am f Dis Child 1988; 142:283-6

17 Salsberry PJ, Nickel JT, Mitch R. Inadequate immunization among 2-year-old children: a profile of children at risk. $f$ Pediatr Nurs 1994;9:158-65.

18 Lopreiato JO, Ottolini MC. Assessment of immunisation compliance among children in the Department of Defense health care system. Pediatrics 1996;97:308-11.

19 Swigonski NL, Skinner CS, Wolinsky FD. Prenatal health behaviors as predictors of breast-feeding, injury, and vaccination. Arch Pediatr Adolesc Med 1995;149:380-5.

20 Guendelman S, English P, Chavez G. The effects of maternal health behaviors and other risk factors on immunizanal health behaviors and other risk factors on immunization status among

21 Stevens-Simon C, Kelly LS, Singer D. Pattern of prenatal care and infant immunisation status in a comprehensive adolescent-oriented maternity program. Arch Pediatr Adolesc Med 1996;150:829-33.

22 Zimmerman RK, Ahwesh ER, Mieczkowski TA, et al. Influence of family functioning and income on vaccination in inner city health centers. Arch Pediatr Adolesc Med 1996;150:1054-61.

23 Marsden EA, Donnelly VM. Social support and it's relationship to immunization status in preschool children. Issues in Comprehensive Pediatric Nursing 1996;192:39-47.

24 Bates AS, Fitzgerald JF, Dittus RS, et al. Risk factors for underimmunization in poor urban infants. $尹 A M A 1994$ 272:1105-10.

25 Larson CP. Efficacy of prenatal and postpartum home visits on child health and development. Pediatrics 1980;66:191-

26 Johnson Z, Howell F, Molloy B. Community mothers' programme: randomised controlled trial of nonprofessional intervention in parenting. BMF 1993;306 1449-52.
27 Janz NK, Becker MH. The Health Belief Model: a decade later. Health Educ $Q$ 1984;11:1-47.

28 Mor. Health Educ $Q$ 1984,11:1-47. to measles immunization. Fournal of the Royal College of General Practitioners 1987;37:25-7.

29 Kviz FJ, Dawkins CE, Ervin NE. Mothers' health beliefs and use of well-baby services among a high-risk population. Res Nurs Health 1985;8:381-7.

30 Becker MH, Nathanson CA, Drachman RH, et al. Mothers' health beliefs and children's clinic visits: a prospective study. f Community Health 1977;3:125-35.

31 Strobino D, Keane V, Holt E, et al. Parental attitudes do not explain underimmunisation. Pediatrics 1996;98:1076-83.

32 Salsberry PJ, Nickel JT, Mitch R. Why aren't preschoolers immunized? A comparison of parents' and providers' perceptions of the barriers to

33 Schmalz K, Larwa L Problems encountered by parents and guardians of elementary school-age children in obtaining guardians of elementary school-age children in obtainin

Keane V, Stanton B, Horton L, et al. Perceptions of vaccine efficacy, illness, and health among inner-city parents. Clin efficacy, illness, and

35 Houseman C, Butterfoss FD, Morrow AL, et al. Focus groups among public, military and private sector: insights to improve the immunization process. Public Health Nursing 1997;142:35-43.

36 Pruitt RH, Kline PM, Kovaz RB. Perceived barriers to childhood immunization among rural populations. $7 \mathrm{Com}-$ munity Health Nurs 1995;12:65-72.

37 QSR. NUDIST [computer program]. Version 3.0. Melbourne: Qualitative Solutions and Research Pty Ltd, 1994.

38 Glaser BG, Strauss A. The discovery of grounded theory: strategies for qualitative research. Chicago: Aldine, 1967.

39 Strauss A, Corbin J. Basics of qualitative research. London: Sage, 1990

40 Irurita VF. Hidden dimensions revealed: progressive grounded theory study of quality care in the hospital. grounded theory study of quality care

41 Harrington P, Woodman C, Shannon W. Vaccine, yes. injection, no: maternal attitudes to the introduction of Haemophilus influenzae type b (Hib) vacccine. Br ₹ Gen Pract 1999;49:901-2.

42 Jones K, Moon G, Clegg A. Ecological and individual effects in childhood immunisation uptake: a multi-level approach. Soc Sci Med 1991;33:501-8.

43 New SJ, Senior ML. "I don't believe in needles": Qualitative aspects of a study into the uptake of infant immunisation in two English health authorities. Soc Sci Med 1991;33:50918

44 The Interagency Committee to improve access to immunization services. The Public Health Service Action Plan to improve access to immunization services. Public Health Rep 1992;107:243-51.

45 Standards for pediatric immunization practices. $7 A M A$ 1993;269:1817-22.

46 Mitchell M. Disadvantaged children. Community Outlook 1985; Sep 11:27-8.

47 Blair A, Davies E, Nebauer $M$, et al. Why immunise? Caregiver understanding of childhood immunisation. Collegian 1997;4:10-17.

48 Bazely P, Kemp L. Increasing attendance at immunisation clinics: lessons from a trial program that failed. Aust $\mathcal{F}$ Public Health 1995;19:459-64.

49 Bennett P, Smith C. Parents attitudinal and social influences on childhood vaccination. Health Education Research 1992; 7:341-8.

50 Coreil J, Augustin A, Halsey NA, et al. Social and psychological costs of preventive child health services in Haiti. Soc Sci Med 1994;38:231-8.

51 McGuire C. Assessing information needs. Health Visitor 1992;65:268.

52 Freed GL, Bordley WC, Clark SJ, et al. Family physician acceptance of universal hepatitis B immunization of infants. 7 Fam Pract 1993;36:153-7.

53 Madlon-Kay DJ, Harper PG. Too many shots? Parent, nurse, and physician attitudes toward multiple simultaneous childhood vaccinations. Arch Fam Med 1994;3:610-13.

54 Woodin KA, Rodewald LE, Humiston SG, et al. Physician and parent opinions. Are children becoming pincushions rom immunizations? Arch Pediatr Adolesc Med 1995;149: $845-9$. 